\title{
Duplicidad uretral incompleta en un varón. Aportación de un nuevo caso
}

\author{
D. Muñoz Vélez, V. Riera Marí, M. Ozonas Moragues \\ Servicio de Urología. Hospital Universitario Son Dureta. Palma de Mallorca \\ Actas Urol Esp 2005; 29 (1): 93-95
}

\section{RESUMEN}

DUPLICIDAD URETRAL INCOMPLETA EN UN VARON. APORTACIÓN DE UN NUEVO CASO

La duplicidad uretral es una rara malformación congénita que afecta mayoritariamente al varón y que se diagnostica en los primeros años de la vida. Presentamos el caso de un varón de 20 años de edad que consultó por la presencia de un doble chorro y de un doble orificio uretral a nivel del glande. La uretro-cistografía retrógrada y miccional mostró la presencia de una uretra con un origen vesical único que se bifurcaba en su porción más anterior, correspondiéndose con una duplicidad tipo IIA2 de la clasificación de Effmann. Descartadas la presencia de otras anomalías, se decidió por la abstención terapéutica.

Palabras claves: Uretra, duplicidad, anomalías congénitas.

\section{ABSTRACT}

INCOMPLETE URETHRAL DUPLICATION IN A MALE. A CASE REPORT

Urethral duplication is a rare congenital anomaly affecting mainly males and being usually diagnosed during paedriatric age. We report a 20 year old male complaining of double urethral meatus with double urinary stream. Physical examination confirmed and additional hypospadic meatus below a normally placed urethral meatus. Retrograde urethro-cystography and voiding cysto-urethrograms showed two distinct urethras originating from a common bladder neck and the diagnosis of Effmann type IIA2 incomplete urethral duplication was made. No treatment was felt to be applied after associated anomalies were ruled out.

Key words: Urethra, duplication, congenital anomalies.

$\mathrm{L}^{\mathrm{a}}$ a duplicación uretral constituye una rara anomalía congénita de la que se han descrito menos de 200 casos en la literatura. En nuestro país, en los últimos 20 años se han publicado 18 $\operatorname{casos}^{1,2,3,4,5}$, de los cuales la inmensa mayoría son varones, siendo descrita esta patología tan solo en 2 niñas ${ }^{6,7}$. Presentamos el caso de un varón que consultó por la presencia de un doble orificio uretral y hacemos un breve repaso de esta inusual patología.

\section{CASO CLINICO}

Varón de 20 años de edad, sin antecedentes personales de interés, que consultó por la presencia de un doble orificio a nivel del glande, uno en posición ortotópica y otro más ventral o hipospádico respectivamente (Fig. 1). Refería la presencia de micciones y eyaculaciones por ambos orificios, siendo de mayor calibre el chorro procedente del orificio ventral. No relataba historia de incontinencia, infecciones urinarias o instrumentación uretral. Se exploraron ambos meatos uretrales con la introducción de una sonda $14 \mathrm{Ch}$, observándose un buen paso de la misma por los dos meatos. La uretrografía retrógrada y miccional mostró una uretra con un origen único a nivel vesical que se duplicaba en forma de lengua bífida en su porción más anterior (Fig. 2). El trayecto principal se correspondía con la uretra ventral. Curiosamente al introducir el contraste por el meato ortotópico este refluía por el meato ventral o hipospádico. Descartadas la presencia de otras anomalías y en ausencia de repercusión funcional se aconsejó la abstención terapéutica.

\section{DISCUSION}

La incidencia real de la duplicidad uretral es desconocida. En una serie reciente de 80 cistouretrografias miccionales en pacientes varones con una edad media de 2,6 meses se detectaron 11 


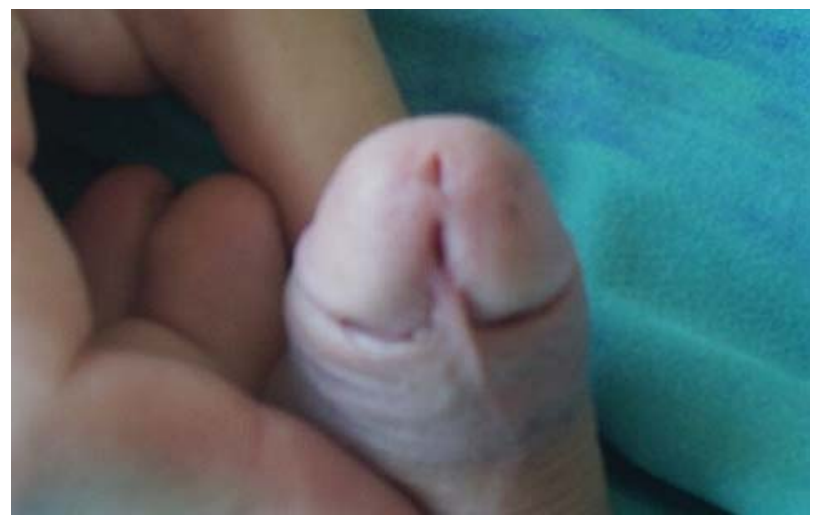

FIGURA 1. Doble meato uretral a nivel del glande.

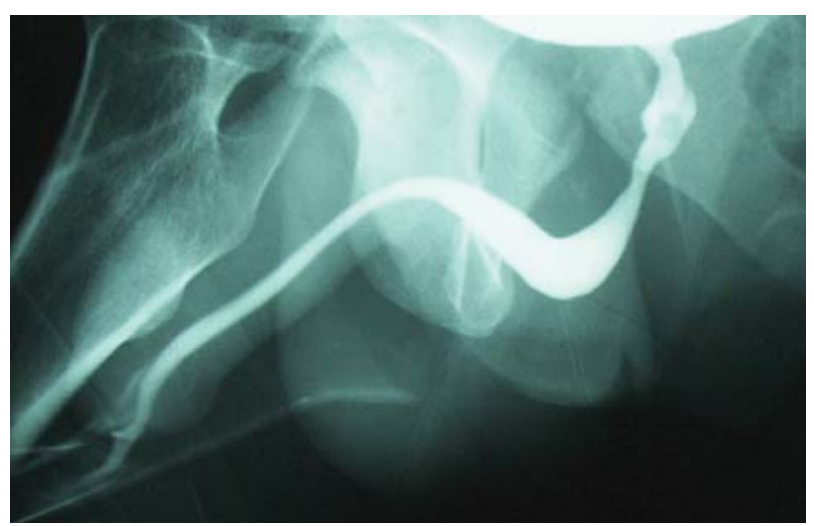

FIGURA 2. Uretrografia miccional que muestra la bifurcación de la porción distal de la uretra.

casos (13\%) de anomalías uretrales, de las que tan solo una fue una duplicidad uretral ${ }^{8}$. Esta anomalía afecta mayoritariamente a varones y con frecuencia se acompaña de otras alteraciones genitourinarias como valvas uretrales posteriores, reflujo vesicoureteral, displasia o agenesia renal, difalía o extrofia vesical. En la mujer es frecuente encontrarla asociada a duplicidad vaginal, vesical y/o uterina ${ }^{9}$. En estos pacientes, también pueden estar presentes malformaciones cardiacas, óseoas (diastasis sinfica) o intestinales (atresia esofágica, duplicidad colónica, imperforación anal).

El origen de la duplicidad uretral habría que atribuirlo a la acción de una noxa que interferiría el desarrollo embriológico de la uretra, el cual arranca hacia la tercera semana de gestación con la migración de las células mesenquimales desde la línea primitiva hasta la membrana cloacal originando los llamados pliegues cloacales, de los que derivaran los pliegues uretrales, los cuales hacia el final del tercer mes se cierran a modo tubular sobre la lámina uretral dando lugar a la uretra peneana. Este proceso se completa hacia el cuarto mes con la formación de la uretra glandular por un mecanismo todavía no definido que puede consistir en la fusión de los pliegues uretrales, la excavación primaria del glande o ambos mecanismos. A diferencia del hipospadias y del epispadias, para la duplicidad uretral con sus diferentes variantes anatómicas, no se ha encontrado una teoría que pueda explicar su génesis embrionaria.

La mayoría de los pacientes se diagnostican en los primeros años de la edad pediátrica aunque todavía algunos casos son diagnosticados en la edad adulta ${ }^{10,11}$.

La forma de presentación clínica más frecuente es la existencia de un doble meato uretral o doble chorro miccional ${ }^{12}$. Otras manifestaciones descritas son la presencia de infecciones urinarias de repetición, reflujo vesicoureteral, incontinencia, obstrucción infravesical o goteo perineal durante la micción.

El diagnóstico se basa fundamentalmente en la exploración física completada con la uretrografia retrógrada, cistografía miccional y uretrocistoscopia. La ecografia y la urografia pueden poner de manifiesto la presencia de otras anomalías urinarias asociadas. Es importante tener presente la posible existencia de signos o síntomas que orienten hacia otras malformaciones no urológicas.

Teniendo en cuenta los planos anatómicos sagital y coronal, más del 90\% de las duplicaciones tienen lugar en el plano sagital ${ }^{13}$. Cuando la duplicación tiene lugar en el plano sagital la uretra ventral normalmente constituye el trayecto funcional principal. El abocamiento del meato uretral accesorio puede ser epispádico, hipospádico, ortotópico o perineal

De las diferentes clasificaciones que pretenden agrupar los distintos tipos de duplicidad uretral conocidos, la más empleada es la de Effmann y cols. (Tabla 1$)^{14}$. Siguiendo la clasificación de Effmann, en una serie de 16 varones con duplicidad uretral, el $25 \%$ fueron de tipo I, el $62.5 \%$ de tipo II y el $12.5 \%$ de tipo III. ${ }^{15}$.

$\mathrm{El}$ caso presentado correspondería con el tipo IIA2 de la clasificación de Effmann en el que el conducto accesorio arranca de la uretra principal y se abre a un meato independiente, es decir pre- 
Tabla 1

Clasificación de Effmann de la duplicidad uretral ${ }^{14}$

Tipo I: Duplicidad uretral incompleta o uretra accesoria ciega

IA: De localización distal. La uretra accesoria se abre en la cara dorsal o ventral del pene sin comunicar ni con la uretra principal ni con la vejiga.

IB: Localizada proximalmente y difícil de diferenciar de un divertículo uretral o de una glándula de Cowper. La uretra accesoria parte de la uretra principal y termina de forma ciega en el tejido periuretral.

Tipo II: IIA: Con dos meatos

IIA1: Dos uretras no comunicadas entre sí que se originan de forma independiente en la vejiga.

IIA2: La uretra accesoria se origina en la uretra principal y termina en un meato independiente. De este grupo existe una variante en Y con un meato abierto al periné.

IIB: Con un meato. Poco frecuente. La uretra accesoria se origina independientemente en vejiga o en la uretra posterior y se fusiona con la principal para terminar en un único meato.

Tipo III: Duplicidad uretral en el contexto de una duplicidad de las estructuras caudales

sencia de dos meatos y de dos conductos que se fusionan antes de entrar en vejiga.

El tratamiento debe ser individualizado en función de la variante anatómica, de la repercusión funcional y de la coexistencia de otras malformaciones. Las opciones van desde la abstención terapéutica, hasta la exéresis de la uretra dorsal accesoria, opción mayoritaria en las duplicidades completas epispádicas, pasando por la meatoplastia aislada, la uretroplastia con colgajo o la resección endoscópica del tabique interpuesto entre ambas uretras ${ }^{16,17}$. Salle y cols propusieron un esquema terapéutico orientador que aparece recogido en la Tabla $2^{15}$.

En este caso al no existir repercusión clínica o funcional significativa se decidió por el momento la abstención terapéutica.

\section{REFERENCIAS}

1. Roa Rico M, Roa Luzuriaga MA, de Blas Gómez V: A case of urethral duplication: nomenclature of the double and bifid urethra and paraurethral ducts in the male. Arch Esp Urol 1983; 36:395-402 (abstract).

2. Sarmentero E, Estornell F, Beamud A, Martínez Verduch M, García Ibarra F: Male complete urethral duplication: report of 3 new cases. Eur Urol 1990;18:276-80.

3. Prado Fernández MC, Gonzalez Landa G, Azpeitia Palomo AM et al.: Duplicidad completa de la uretra. Arch Esp Urol 1990, 43:294-5.
Tabla 2

Esquema terapéutico propuesto por Salle y cols. ${ }^{15}$

\begin{tabular}{ll}
\hline \multicolumn{1}{c}{ Tipo } & \multicolumn{1}{c}{ Tratamiento } \\
\hline IA & $\begin{array}{l}\text { Meatoplastia o exéresis de la uretra } \\
\text { accesoria }\end{array}$ \\
IB & Abstención terapéutica \\
IIA1 & $\begin{array}{l}\text { Uretro-uretrostomía o exéresis de uretra } \\
\text { accesoria con o sin uretroplastia }\end{array}$ \\
IIA2 & Uretroplastia \\
IIB & Abstención terapéutica \\
III & \\
\multicolumn{1}{c}{ Coronal: } & \\
\multicolumn{1}{c}{ Sin difalia } & $\begin{array}{l}\text { Exéresis del septo vesical o la hemivejiga } \\
\text { + reimplante ureteral en vejiga }\end{array}$ \\
& contralateral. Para la uretra lo mismo \\
& que para el tipo IIA1. \\
Con difalia & $\begin{array}{l}\text { Penoplastia + glandeplastia. Para la } \\
\text { vejiga el esquema anterior }\end{array}$ \\
Sagital & $\begin{array}{l}\text { Exéresis de la vejiga no funcional. Para } \\
\text { la uretra lo mismo que IIA1 }\end{array}$ \\
&
\end{tabular}

4. Marti Camps M, Rodo Salas J, Morales Fochs L: Duplicidad uretral completa. Arch Esp Urol 1995 ;48:614-8.

5. Castiñeiras J, Parra R, López A et al.: Duplicidad uretral. Aportación de dos variedades clínicas. Actas Urol Esp 1994; 18: 323-7.

6. Antón Pacheco J, Ruiz de la Roja JC, Martín Oses E, Sánchez Sánchez E, Lujan Galán M: duplicidad completa en una niña.Actas Urol Esp 1996; 20:669-71.

7. Berrocal T, Novak S, Arjonilla A, Gutierrez J, Prieto C, Urrutia MJ: Complete duplication of bladder and urethra in the coronal plane in a girl: case report and review of the literature. Pediatr Radiol. 1999 ;29:171-3.

8. Chaumoitre K, Merrot T, Petit P, Sayegh-Martín Y, Alexandrin $\mathrm{P}$, Panuel M: Voiding cystourethrography in boys. Does the presence of the catheter during voiding alter the evaluation of the urethra?. J Urol 2004, 171: 1280-1.

9. Gastol P, Baka-Jakubiak H, Skobejko-Wlodadaska L, Szymkiewz C: Complete duplication of the bladder, urethra, vagina and uterus in girls. Urology 2000, 55:578-81.

10. Rodríguez Alonso A, Crespo Outeda E, González Blanco A, et al. Duplicidad de uretra masculina. Actas Urol Esp 2002; 26:69-73.

11. Menéndez Villalba C, Gutierrez Novoa J, Guitan Rodríguez C: Duplicidad uretral: a propósito de un caso. Arch Esp Urol 1993; 46:816-8.

12. Psihramis KE, Colodny AH, Lewobitz RL, Retik AB, Bauer SB: Complete patent duplication of the urethra. J Urol 1986, 136:63-7.

13. Woodhouse CR, Williams DI: Duplications of the lower urinary tract in children. Br J Urol 1979, 51: 481-7.

14. Effmann EL, Lebowitz RL, Colodny AH: Duplication of the urethra.. Radiology. 1976 Apr;119:179-85.

15. Salle JLP, Sibai H, Rosenstein D, Brzezinski AE, Corcos J: Urethral duplication in the male: Review of 16 cases. J Urol 2000; 163: 1936-40.

16. Melchior H: Duplication of the urethra. Transurethral treatment. Eur Urol 1975 1:243-4

17. Podesta ML, Medel R, Castera R, Ruarte AC: Urethral duplication in children: surgical treatment and results. J Urol 1998; 160:1830-3.

Dr. Daniel Muñoz Vélez

Rupit, 58 - Bajo

07013 Palma de Mallorca.

(Trabajo recibido el 16 marzo de 2004) 